Artigos 



\title{
Fenomenologia da Comunicação em sua quotidianidade
}

\author{
Fábio Fonseca de Castro*
}

\section{Resumo}

$\mathrm{O}$ artigo reflete sobre a relação entre a Comunicação e os processos comunicativos quotidianos à luz do pensamento de Martin Heidegger. Pretendende-se interpretar o fenômeno comunicativo a partir de uma abordagem hermenêutica e fenomenológica, investiga-se a Comunicação como condição tácita de todo estar no mundo e discute-se o caráter banal e quotidiano da Comunicação por meio da noção heideggeriana de falatório (Gerede), a qual procura entender como experiência comunicativa fundamental. $\mathrm{O}$ objetivo do artigo é compreender a Comunicação na sua condição fenomênica mais elementar, que identificamos como sendo a sua condição intersubjetiva. Com essa proposição, o artigo procura pensar a Comunicação sem as amarras metafísicas que exigem que se pense, nela, como uma condição de eficiência de linguagem e de sentido, iniciando uma fenomenologia da Comunicação que a perceba como fenômeno intersubjetivo e quotidiano.

Palavras chave: Comunicação. Fenomenologia. Heidegger. Cotidiano. Intersubjetividade.

\section{Phenomenology of communication in everyday life Abstract}

The article reflects on the relationship between Communication and communicative everyday processes using Martin Heidegger's philosophy. Intending to interpret the communicative phenomenon from a phenomenological and hermeneutical approach, we seek to understand Communication as tacit condition of every being in the world and we discuss the banal and quotidian character of Communication through Heidegger's notion of idle talk (Gerede), comprehen-

* Professor doutor da Faculdade de Comunicação e do Programa de Pós-graduação Comunicação, Cultura e Amazônia no Instituto de Letras e Comunicação da Universidade Federal do Pará (UFPA). Belém-PA, Brasil. Email: fabio.fonsecadecastro@gmail.com 
ded it as a fundamental communicative experience. The aim of the paper is to understand the Communication in its most basic phenomenal condition, wich we have identified as their intersubjective condition. With this proposition, the article also seeks to understand Communication without the metaphysical bonds that are required to think on it, in other words a condition of effectiveness of language and meaning. Doing this, we start a phenomenology approach by which Communication could be comprehended as intersubjective and daily phenomenon.

Keywords: Communication. Phenomenology. Heidegger. Everyday. Intersubjectivity.

\section{La fenomenología de la Comunicación en la vida cotidiana Resumen}

El artículo reflexiona sobre la relación entre la Comunicación y los procesos comunicativos cotidianos a la luz del pensamiento de Martin Heidegger. Con la intención de interpretar el fenómeno comunicativo con un enfoque fenomenológico y hermenéutico, tratamos de comprender la Comunicación como condición tácita de todo ser en el mundo y analizamos el carácter banal y cotidiana de la comunicación a través de la noción heideggeriana de habladuría (Gerede) que trata de entender como experiencia comunicativa fundamental. El objetivo de este trabajo es entender la Comunicación en su estado fenomenal más básico, se ha identificado como su condición intersubjetiva. Con esta propuesta, el artículo trata de pensar en Comunicación sin los lazos metafísicos que requieren a pensar en ella como condición de eficacia de lenguaje y de significado, empezando una fenomenología de la Comunicación que la piense como fenómeno intersubjetivo y cotidiano.

Palabras clave: Comunicación. La fenomenología. Heidegger. Cotidiano. Intersubjetividad.

\section{Introdução}

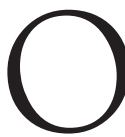

propósito deste artigo é refletir sobre a relação entre Comunicação, em geral, e os processos comunicativos quotidianos, em particular, à luz da fenomenologia existencial de Martin Heidegger. Indagamos de que maneira o pensamento desse filósofo pode contribuir para a reflexão sobre a Comunicação e exploramos, em particular, a hipótese de pensar o fenômeno comunicativo por meio da compreensão heideggeriana do falar banal (Gerede), presente na intersubjetividade quotidiana. Desenvolvemos nossa reflexão por meio de uma abordagem 
filosófica, e especificamente hermenêutica e fenomenológica, do fenômeno comunicativo.

Num plano mais amplo, abordamos a dimensão da quotidianidade do Dasein - o ser-aí, categoria fundamental da analítica heideggeriana - enquanto processo comunicativo geral e, dessa forma, banal. Num plano mais específico, discutimos a condição mais evidente desse estar-no-mundo, por meio da noção de falatório (Gerede), que procuramos entender como experiência comunicativa fundamental do Dasein.

No primeiro tópico após esta introdução procuramos sintetizar o pensamento de Heidegger sobre a noção de quotidiano observando, particularmente, como as circunstâncias da interação e da Comunicação constituem elementos fundamentais para a sua caracterização. Também aí, esclarecemos como o filósofo compreende o quotidiano como uma situação de "queda" do ser no mundo da vida. Procuramos explicitar essa noção de "queda" em seu estatuto ontológico, ou seja, sem a aferição de valor, atitude que é própria da metafísica. Não se trata, assim, de uma "queda" numa eventual negatividade, ou mesmo em um não-sentido. É, simplesmente, a descida, o trânsito do Dasein em direção ao mundo, à essa quotidianidade na qual ele oblitera a questão sobre o sentido do ser, que constitui o caminho comum de sua existencialidade ${ }^{1}$.

No tópico seguinte, observamos a dimensão do falatório, a Gerede de que nos fala Heidegger, na conformação comunicativa dessa

\footnotetext{
${ }^{1}$ A noção heideggeriana de queda (Verfallenheit) tem sido refletida, pelos autores que trabalham com o filósofo, de maneira complexa e mesmo divergente. Enquanto um grupo deles, como Guignon (2002), Haugeland (2002), Magnus (2002), Riviale (2010), dentre outros, compreende que Heidegger pensa a queda - e a situação análoga da inautenticidade - como uma depreciação da experiência da vida comum e pública, talvez mesmo da democracia e, eventualmente, como um sucedâneo da ancestral desconfiança platônica com toda doxa, outro grupo, que agrega Gelven (1989), Pasqua (1993), Blattner (2006), Guest (2008), dentre outros, compreende a queda, juntamente com a inautenticidade, como, simplesmente, o estatuto ontológico do fechamento da questão existencial. Nesse contexto de interpretação, quando falamos em "ilusões", por exemplo, temos, simplesmente, um fato do pensamento, e não uma avaliação moral ou cultural de determinados eventos.
} 
quotidianidade. Procuramos explicitar esse conceito, mostrando como o falar, o discurso (Rede) se banaliza enquanto falatório ao adentrar na vida quotidiana. Procuramos compreender o falatório como o manifestar comunicativo do Dasein em sua quotidianidade.

Por fim, no último tópico do artigo, discutimos a banalidade da Comunicação como fenômeno, refletindo sobre seu papel nesse mundo do quotidiano. Procuramos compreendê-la sem as amarras metafísicas, que nos exigem pensar Comunicação como uma condição de eficiência de linguagem e de sentido e, para isso, situamo-la como, fundamentalmente, uma experiência de comutação do banal, de construção coletiva da superficialidade e do não-dizer.

\section{Quotidianidade e Comunicação em Heidegger}

Há dois fatos filosóficos a notar a respeito da Comunicação, quando pensamos nela a partir da analítica existencial de Heidegger. $\mathrm{O}$ primeiro, é que a experiência da Comunicação se dá no quotidiano e enquanto quotidiano. $\mathrm{O}$ segundo, que a experiência da Comunicação se dá no plano do ser-com-outros (Mitsein), já que corresponde, necessariamente, a um contato - entre dois ou mais indivíduos, em qualquer plano: o contato interpessoal direto ou mediado.

Para compreender o que significa, em Heidegger, a ideia de quotidiano, ou de quotidianidade, é preciso observar que, para o filósofo, ela não é análoga às ideias de "vida quotidiana" ou de "vida comum". Para Heidegger, seria a estrutura constitutiva original e incontornável de todo ser-no-mundo. É o universo do ser-com-outros, no qual o ser-com-outros sempre prevalece sobre o ser-a-si-mesmo que se poderia ser, de outro modo.

Nesse mundo, o Dasein cede lugar ao Se. É o universo do se é, se diz, se faz, se vê, se sabe... Mesmo quando se diz "Eu", está-se pensando nesse nós despessoalizado que é o se. Nesse estar-junto o Dasein se torna anônimo, se eclipsa. Segundo Harr, intérprete de Heidegger, a quotidianidade presente nesse se "designa uma substitutividade indefinida de papéis, situações, gestos, palavras 
que, longe de permanecer exterior (ao indivíduo), constitui seu primeiro 'eu mesmo"' (HARR, 1989, p.213).

É assim que se produz o fenômeno da queda (Verfallenheit), a auto-identificação do Dasein como mais uma coisa-no-mundo. É a queda que leva ao encobrimento do ser e à inautenticidade do Dasein. No mundo da queda, do ser encoberto e inautêntico, tem-se a ilusão de que se tem "individualidade", "identidade" etc, quando tudo isso, efetivamente, não passa de um encobrimento, de uma fuga, das questões existenciais que se colocam ao Dasein.

$\mathrm{O}$ segundo fato, referente ao caráter interativo da Comunicação, deriva da evidência de que o Dasein constitui, inexoravelmente, também, um Mitsein. Em termos heideggerianos, o primeiro é co-existenciário ao segundo. $\mathrm{Na}$ verdade, dizer que a experiência da Comunicação ocorre no plano do ser-com-outros pode parecer redundante, para quem está familiarizado com o pensamento de Heidegger, porque, como se sabe, o Dasein é, fundamentalmente, ser-com-outros. Porém, esse fato inverte a lógica com a qual se constrói o pensamento epistemológico-metafísico sobre a Comunicação, que não a tem como uma inerente intersubjetividade, mas sim como um fluxo de consciências, umas em direção a outras.

Assim, a concepção heideggeriana do Dasein, do ser-aí, como, necessariamente, um ser-com-outros (Mitsein), constitui um elemento central do pensamento do filósofo sobre a Comunicação. $\mathrm{Na}$ verdade, a percepção do Dasein como um ser-com, é constitutiva da própria gênese vocabular de Ser e Tempo. Como assinala Cavalcante $(1993$, p.318) a respeito do Dasein, "todas as suas concretizações na existência exercem uma ação expressa pela preposição com (mit)". Mesmo isolado, mesmo solitário, o Dasein é, sempre, Mitsein. O mundo é sempre mundo compartilhado (Mitwelt); o viver é sempre convivência (Miteinandersein) (CAVALCANTE, 1993, p.318). Na mesma direção, Boutot afirma que, "Mesmo só, mesmo quando não tem nenhum outro ser na sua proximidade imediata, o Dasein está, sempre, com alguém. A solidão não tem sentido, a bem dizer, senão para um ser que está, fundamentalmente, em relação com outros" (BOUTOT, 1989, p.29). 
Mesmo sendo redundante dizê-lo, nos parece fundamental reafirmar essa ideia, em primeiro lugar, para que se perceba que o caráter comunicativo do Dasein é inerente à sua condição existencial e, em segundo lugar, para que se evite uma compreensão metafísica da ideia de Comunicação, assimilando-a não como uma condição existencial, mas como uma condição de eficácia no processo de interação entre indivíduos ou, pior ainda, como o processo de transmissão de mensagens.

Esses dois fatos, ou temas, heideggerianos, são convergentes. O mundo do quotidiano, o mundo do se, ocorre em função da co-existencialidade entre o Ser-aí e o ser-com-outros, ou seja, em função da evidência de que o Dasein constitui, inexoravelmente, um Mitsein. É no quotidiano que o ser é com outros e, em consequência, é quando é com outros - no quotidiano, portanto - que o ser se comunica.

O mundo do se permite as ilusões do Dasein. É um mundo cômodo, que the exime de formular as questões sobre sua existência e, assim, de dissimular, na metafísica da vida comum, sua pretensão de integralidade, totalidade e identidade. A dispersão entre os outros the confere um abrigo, equivale ao fazer parte de um coletivo de incógnitos, a estar no seio da manada.

Harr (1975, p.214-215) menciona as ilusões prementes do Dasein na sua quotidianidade, circunstância na qual toda pretensão à integralidade, totalidade e identidade se esvai sem que, no entanto, o Dasein tenha qualquer percepção desse fato:

O ser do mundo quotidiano nos força a tornar nossas, antecipadamente, as vias já traçadas e percorridas, as condutas prescritas, as ideias recebidas. Porque, mais uma vez, todo mundo quer, honestamente, lucidamente e com todas as suas forças, ao que parece, 'se realizar' (como se diz!). Todo mundo se orgulha de ter sua própria opinião sobre o que dizem os jornais, de ter uma 'margem de manobra' no interior das imposições 'sociais' que ninguém contesta. Todo mundo se acha capaz de se diferenciar do ser 'médio e ordinário' (durch-schnittlich) que, como se crê, lhe é proposto e não imposto.

A pretensão a ter-se opinião, a se realizar, a se comunicar, dentre outras quaisquer, traem o seu anunciado propósito. 
$\mathrm{O}$ que pode significar, no mundo do quotidiano, se ter uma opinião sobre o que dizem os jornais? Ou então se sentir como parte de uma qualquer nação? $\mathrm{Ou}$, um se entender, com alguém, a propósito de algo? Ou, ainda, acreditar que se pode ter uma "margem de manobra", garantida pela própria consciência, no interior das determinações sociais?

Para o sujeito imerso na sua quotidianidade, isso tudo diz respeito à coesão do mundo, à ideia de que o mundo tem uma ordem e está em ordem. É, talvez, o pensamento do Dasein, com honestidade e lucidez, como diz Harr, em seu quotidiano. Mas esse significar só tem sentido enquanto sentido banal. Processada a analítica existencial que Heidegger opera, o que vemos não é mais essa coerência e essa integridade do ser, mas, apenas, a ilusão transcendental, por meio da qual o Dasein acredita que cabe a ele, que está nele, a possibilidade de apreender o absoluto do ser que "é" ou do qual participa (RIVIALE, 2010, p.10). O se do Dasein é sua ilusão de mundo - e, assim, por extensão, a sua Comunicação enquanto processo, ou ato, quotidiano.

\section{O 'falatório' como experiência comunicativa e como queda do Dasein na sua quotidianidade}

Para compreender a dimensão comunicativa e quotidiana do Dasein, procuramos nos concentrar na noção de Gerede, de difícil tradução mas que evoca, de maneira forte, ideias como senso comum, opinião corrente, bate-papo e falatório. Em língua espanhola tem sido comum a tradução do termo por habladuria, que não tem equivalente em português, mas que ajuda a compreender a extensão do termo quando consideramos o espírito comum das duas línguas ${ }^{2}$. Na obra de Heidegger, num sentido mais erudito, também há uma associação com a ideia de publicidade, Öffentli-

\footnotetext{
${ }^{2}$ Procurando comparar as escolhas de tradução para a terminologia heideggeriana, percebemos que, em francês, Gerede tem sido traduzido por bavardage, escolha tanto da tradução de Martineau (Authentica, 1985) como da de Vezin (GALLIMARD, 1986). Em inglês, por idle talk, presente na tradução de Mcquarrie (SCM Press, 1962) e de Stambaugh (State University of New York Press, 1996).
} 
chkeit, sempre no sentido de algo que, tornado público, se torna permissível a todos; sobre o que todos podem falar, dizer algo ${ }^{3}$.

O prefixo ge- da palavra indica coletividade, conjunto, como Gebirge (cordilheira) e Geschwiste (irmãos, frátria). Literalmente, indica "o conjunto do que é referido", a soma, o acúmulo - e, nesse sentido, também o transbordo, o excesso e, em consequência, o vazio.

Gerede evoca uma vacuidade no dizer, o excesso de sentido que leva à ausência de sentido. A vacuidade no dizer é uma condição típica da Öffentlichkeit - publicidade, no sentido de tornado público, sabido por todos - e a partir das expressões öffnen (abrir), offenbar (suscetivel de abertura) e öffentlich (algo que está aberto a todos) (HEIDEGGER, 1976, p.126-128).

Outra evocação possibilitada pelo termo é a noção de Sicht (Heidegger, 1976, p.69-70), que traduziríamos em português literal como "vista", em português corriqueiro como "olhadela", "espia" ou "espiada", um conhecimento intuitivo que se produz por livre associação, por cognição. É algo que se realiza no instante: o vendo, o percebendo - ou melhor, o "sacando", gíria que, a nosso ver, explica totalmente a ideia. Cabe lembrar que, em Heidegger, Sichté um termo paralelo a Umsicht (visão periférica, circunvisão) e à palavra Rücksicht, literalmente "olhando para trás", mas no sentido de "ter respeito por algo ou alguém", "levar algo ou alguém em consideração". O Sicht se assemelha a uma iluminação (Gelichtetheit), a uma abertura para o mundo tal como ele se apresenta numa determinada conjuntura. O Sicht é um processo natural do Dasein; e fundamental no seu estar no mundo. É um modo pelo qual o indeterminado se substantivisa, se torna algo.

O falatório dá, ao Dasein, uma possibilidade de viver-seu-tempo, de ser-consigo-mesmo (bei ihm selbst). É a possibilidade da livre prospecção, uma liberdade perscutiva que o projeta no futuro

\footnotetext{
${ }^{3}$ Optamos pela expressão falatório porque ela, a nosso ver, favorece a percepção do caráter de novidade instigante, de opinião carregada de afeto, de opinião impressiva, de opinião banal e de opinião que se espalha com rapidez - elementos que vemos presentes no pensamento de Heidegger a respeito do Dasein, que está em meio a outros Dasein e entes comuns do mundo quotidiano.
} 
- o "falatório" visa o futuro. O Dasein que experimenta o falatório é um ser-no-futuro (Zukünftigsein). O Dasein que experimenta o falatório se confunde com o tempo: ele já não está no tempo, mas é o tempo. O "falatório" dá tempo ao Dasein: configura o presente no futuro e acomoda o passado.

Feitas essas considerações sobre o sentido do falatório, podemos percebê-lo no uso heideggeriano, o qual a tem como uma experiência do quotidiano.

Há duas formas de Comunicação em Heidegger: aquela que se dá com o falar (Rede), e que consiste na voz existencial do Dasein, na sua construção ontológica ${ }^{4}$, e aquela que habita o quotidiano e que, em nossa compreensão, diz respeito, fundamentalmente, ao falatório. No $\$ 35$ de Ser e Tempo Heidegger trata da maneira como o falar (Rede) se torna mero falatório. Ele adverte que a expressão não é pejorativa, já que sua abordagem é sempre ontológica. Não está fazendo uma crítica moralizante ou uma filosofia da cultura (PASQUA, 1993, p.80). Nesse sentido, falatório tem um sentido positivo, à medida em que "Significa, terminologicamente, um fenômeno positivo que constitui o modo de ser do compreender e do explicitar do Dasein quotidiano" (HEIDEGGER, 1976, p.223).

Falatório é o falar banal, diário, o falar por falar, sem que leve, necessariamente, a uma compreensão. Esse evento diminui ou esgota a Comunicação, pois, como diz Pasqua, "se os interlocutores entendem a mesma coisa é porque eles se movem num falar-em-comum para o qual o que importa, antes de tudo, é

${ }^{4}$ Literalmente, Rede significa discurso, em português e assim é traduzido na edição brasileira de Ser e Tempo. Não obstante, essa tradução apresenta um problema, porque Heidegger não está se referindo àquilo que nós entendemos por discurso - ou seja, um determinado conjunto de enunciados que possuem, conscientemente ou não, vínculos intersubjetivos e ideológicos - mas sim à reflexividade não banalizada do Dasein. Para utilizar uma expressão do Heidegger tardio, podemos dizer que a palavra discurso já foi "enfeudada" pela metafísica tradicional, de forma que não podemos utilizá-la sem nos remetermos ao sentido corrente com que se usa o termo - e que pertence, assim, ao campo do falatório - de discurso como algo previamente elaborado, que se alcança ou não. Por essa razão, seguimos a opção de Martineau de traduzir Rede, simplesmente, como "o falar" (le parler). Nossa intensão é garantir o sentido aberto, ontológico, com que Heidegger utiliza o termo. 
falar" (PASQUA, 1993, p.80). Nesse ato, a Comunicação cessa de comunicar.

Pode-se deduzir que, por Comunicação, Heidegger não entende um falar-em-comum, ou o fato de entender "a" mesma coisa que os interlocutores. Sendo isso o terreno do falatório - e, por extensão, da Comunicação, no mundo na vida, no mundo do quotidiano, - é senão uma ideia referencial, metafísica, que diz respeito a uma condição que, efetivamente, não é alcançável senão na vida quotidiana.

O falatório é uma experiência que se processa no Mitsein do Dasein - ou seja, do estar junto desse indivíduo - que somos cada um de nós, humanos - em nossa faculdade de indagar sobre o que somos e estamos a fazer. Mitsein, ser-com-outros, é uma expressão igualmente central para construirmos nossa leitura e é, em Heidegger, a base de uma teoria da intersubjetividade. Podemos associá-lo à experiência da interação social, em geral, procurando trazer a fenomenologia existencial para um campo sociológico e, especificamente, para a dimensão comunicativa da experiência social. Enquanto experiência do Mitsein, o falatório consiste num fenômeno comunicativo e interativo.

O falatório é a atitude de compreender uma coisa sem apropriação prévia do assunto. Ele tem uma dimensão negativa, representada por sua banalidade, imprecisão e futilidade e, também, uma dimensão positiva, representada pela possibilidade de que, por meio dela, o Dasein compreenda, ou compreenda melhor, os fenômenos que ocorrem ao seu redor.

Apesar de Heidegger abordar a quotidianidade do Dasein por meio do que seriam, segundo ele, as suas três formas características - ambiguidade (Zweideutigkeit), curiosidade (Neugier) e falatório (Gerede), - pensamos que esta última ocupa um lugar especial na descrição do Mitsein. $O$ falatório nos parece a mais importante, porque corresponde a um estar-no-mundo característico, enquanto que as outras duas são peculiaridades desse processo.

Na verdade, esses três processos são coetâneos e simultâneos: o falatório se realiza por meio da ambiguidade e da curiosidade. A ambiguidade representa o fato de que o Dasein nunca pode ter 
certeza sobre a autenticidade e sobre a veracidade do seu encontro com aquilo que encontra no dia a dia. Por "aquilo" se deve entender os entes: eventos, objetos, processos e outros Dasein. Quais desses encontros seriam "genuínos"? E quais, dentre eles, seriam envolvidos pelo manto ambíguo do "falatório" - do que é, publicamente, interpretado? Da mesma forma: quanto de ambiguidade não está presente na maneira como o Dasein projeta a si mesmo, no seu encontro com o mundo? - afinal, a publicidade de si-mesmo também atravessa o falatório, também é publicamente interpretada.

Já a curiosidade (Nengier) representa a dificuldade que tem o Dasein de concentrar sua atenção, seu interesse, naquilo que vê. O Dasein é marcado pela dispersão (Zerstreuung), por uma "incapacidade de permanecer" (Unverweilen) no mundo que o circunda. Heidegger utiliza um vocabulário variado, rico de expressões, para descrever esse processo. Além desses dois termos, é bem conhecida sua caracterização da curiosidade do Dasein como uma "carência de morada" (Auf enthaltslosigkeit).

O tema remete, é claro, à crítica agostiniana da tentação (tentatio) da curiosidade (curiositas) - aliás, já comentada por Heidegger nos seus cursos sobre a fenomenologia da religião, em 1920-21 - uma concupiscentia oculorum, que Agostinho condena, sobretudo, quando o indivíduo se deixa atrair por alguma das três perversa scientia - magia, mística e teosofia - que, segundo ele, podem levar a uma ruína do indivíduo. Também para Heidegger (1976, p.226-228) a curiosidade é um fator que pode provocar a queda do Dasein.

Pode-se compreender a curiosidade e a ambiguidade como os elementos de ação do falatório; como seus impulsores. Assim, toda compreensão - e toda projeção, afinal -, no dia-a-dia, é ambígua e se deve à essa curiosidade pelo banal. $\mathrm{O}$ falatório resulta da concretização discursiva dessa ambiguidade e dessa curiosidade.

Como diz Heidegger, "o falatório é a possibilidade de a tudo compreender sem apropriação prévia da coisa” (HEIDEGGER, 1976, p.224). Ou seja, se não há o que compreender, todos podem compreender. Na verdade, compreender o que é o falatório é a maneira mais fácil de entender o que é a queda (Verfallenheit) do 
Dasein, o encontro do Dasein com o mundo - uma ideia também presente em Gelven, para quem, "talvez seja sob a forma do falatório que a metodologia presente na interpretação heideggeriana que a queda seja mais óbvia" (GELVEN, 1989, p.107).

O Dasein que se atém ao falatório se distancia cada vez mais de seus vínculos ontológicos com o mundo. Ele se desenraíza. É um fenômeno presente no humano, em geral, mas que encontra novas forças, novas dinamizações, com os processos de tecnologização da experiência social e particularmente com a tecnologização da experiência comunicativa.

A consequência do falatório sobre a existencialidade do Dasein é que, por meio dele, o Dasein se esconde, se perde (verloren) na existência coletiva do se (das Man): "perdendo-se no domínio público do se e no seu falatório, o Dasein deixa de entender, entendendo o se-mesmo do seu próprio si-mesmo" (HEIDEGGER, 1976, p.361). A queda do Dasein no mundo quotidiano lhe impõe, pois esse mundo do entre-dito e da dispersão do si-mesmo, que é o mundo comum do se.

\section{Sobre a banalidade da Comunicação como fenômeno}

mundo do quotidiano, segundo Heidegger, é um mundo de esquecimento do sentido do Ser e de inautenticidade para esse mesmo Ser. Submerso num ambiente banal de dispersão e de curiosidades múltiplas, envolto num crescendo polifônico de vozes e discursos que não se completam, esse Ser, que somos nós quando pensamos no que significa o Ser que somos - e que fomos, simplesmente, sem mais explicações, jogados aí, nesse mundo, se abriga nele próprio como quem se protege do vazio e do silêncio que levam à questão sobre o sentido do Ser.

Sim, estamos falando do nosso mundo. O mundo do quotidiano sempre foi o nosso mundo. A técnica e, com ela, a midiatização da realidade, o banalizam, o quotidianizam, ainda mais. A Comunicação, enquanto fenômeno da linguagem, pode até abrir clareiras para o Ser recuperar sua autenticidade, mas, em geral, se deixa levar pela tentação fácil da repetição vazia da fala. A Comu- 
nicação midiatizada, podemos deduzir, contribui para intensificar ainda mais essa experiência de dispersão, curiosidade e de estar-se envolto na polifonia de vozes que povoa o mundo, esse falatório inconstante que dá ao Ser toda a sua quotidianidade.

Mas atenção: esse mundo quotidiano não deve ser avaliado, necessariamente, de maneira negativa. Imersos na grande metafísica ocidental, temos tendência a perceber esse mundo, banal e inautêntico, como um mundo imperfeito, irreal e falso. Heidegger (1976, p.222) alerta que não é assim que ele deve ser visto. Ele é, simplesmente, o mundo no qual somos, no qual estamos.

A vida quotidiana é a vida do Dasein na experiência de sua queda (Verfallenheit). E queda, de acordo com Heidegger, é a condição existencial do Dasein que vai de encontro ao mundo e ao convívio seguro com os outros. É o mundo social dos homens. É o mundo fundamental, o mundo comum, o mundo no qual habitamos.

Há uma conexão, uma mútua implicação, entre falatório, curiosidade e equívoco. O filósofo procura interpretar, ontologicamente, essa ligação, dizendo que ela exprime, na prática, um modo de ser fundamental da existência: justamente, a queda. Mas, atenção, para que se compreenda o que Heidegger quer dizer por queda é preciso seguir o raciocínio ontológico e seguir sem atribuir a essa queda um valor negativo. É preciso vê-la somente como uma dimensão existencial do ser-no-mundo: a dimensão própria do Ser em sua quotidianidade ${ }^{5}$.

Evidentemente há uma tendência cultural, derivada da própria metafísica, a compreender-se inautêntico como algo negativo e autêntico como algo positivo. Da mesma maneira, a queda, associada ao inautêntico, não é, em si mesma, uma condição existencial negativa: é a queda do Ser no mundo, na sua quotidianidade

\footnotetext{
${ }^{5}$ A noção de queda resulta de uma espécie de metamorfose daquilo que Heidegger chamava, em sua obra anterior a Ser e Tempo, de ruinância (Ruinanz) (GREISCH 1994, p.226). Em Ser e Tempo, o tema é introduzido no \$9, onde Heidegger fala sobre a inautenticidade (Uneigentlichkeit). A queda (Verfallenheit) é uma variação desses conceitos. Greisch define a relação entre a queda e a inautenticidade dizendo que esta é um "estado", enquanto a primeira é um movimento, por meio do qual o Dasein "volta as costas" para si mesmo e se "abandona ao mundo" (GREISCH 1994, p.226).
} 
repleta de impressões vagas que, fundamentalmente, resultam num distanciamento do Ser em relação a suas questões ontológicas. Heidegger (1976, p.231-232) adverte, enfaticamente, que o termo queda não representa uma "apreciação negativa" (negative Bewertung), mas sim o envolvimento do Dasein com o modo de Ser comum do mundo, com sua pouca disposição em indagar a respeito do Ser - ou melhor, formular as questões referentes ao Ser.

Esse equívoco possui, aliás, similaridade com outros eventuais equívocos presentes na cultura. Por exemplo, a noção heideggeriana de queda não deve ser entendida, tal como o é, pela teologia em geral, como status corruptionis, tal como definido na doutrina do pecado original, na qual a palavra queda tem um lugar destacado ${ }^{6}$. Também não se deve compreender queda tal como - novamente - a teologia a refere enquanto "propriedade ontológica má e deplorável” (HEIDEGGER, 1976, p.232), que a evolução da humanidade deixa para trás. E, por fim, não deve, ainda, entendê-la enquanto a "visão noturna" (Nachtansicht) do Dasein: ou seja, uma percepção do Dasein como algo anódino, advertência dirigida por Heidegger ao irracionalismo.

A queda é, assim, um anátema do fenômeno do existir. $\mathrm{O}$ termo existir provém de ek-sistire, no qual o prefixo grego ek (ou ex) evoca a ideia de projetar para fora. Nesse sentido, o ser ek-siste, ou seja, sai de sua condição mais imediata, que é a da sua materialidade como ente. Em outras palavras, reflete sobre o que é, o que remete à compreensão de que o pertencimento do ente ao ser equivale a uma despossessão de si. Existir significa, assim, sair do ente, elaborar a questão sobre o sentido de ser. É uma propriedade

\footnotetext{
${ }^{6}$ A ideia cristã de pecado original supõe uma relação entre ser e ente concebidos como criador e criatura. Não é disso que Heidegger fala. Para ele, a queda se dá exclusivamente nos limites do Dasein, significando que ele se observa ou são enquanto ser. Como observa Pasqua (1983, p. 85), a queda é um movimento que ocorre dentro do Dasein ele-mesmo. Para Heidegger, se a palavra pecado tem um sentido, esse sentido está no fato de que pecado é um sentido qualquer que, como qualquer outro, afeta o Dasein: não ética ou moralmente, e sim, apenas, ontologicamente. Uma perceção associável à compreensão do mal à maneira dos gnósticos.
} 
do Dasein: por meio da reflexão sobre a finitude do seu corpo, do seu ente, existir significa se distanciar de sua condição imediata.

No quotidiano, no mundo, o Dasein ignora essa relação ontológica. Evita refletir sobre sua condição de inerente finitude e, assim, transforma a existência num simples estar no mundo. No quotidiano, ser e existência se confundem, como se fossem a mesma coisa. É, pois, preciso distinguir entre o ente - intramundano como seja - e o ente que tem um ser. É nesse sentido que, se existir não coincide, necessariamente, com o estar presente, essa coincidência se torna imperativa na vida quotidiana. Além disso, essa coincidência tem um nome: queda, a queda do sentido do ser no mundo, que é a condição existencial presente no falatório, na curiosidade e no equívoco.

Ela também demarca a diferença entre o viver autêntico e o viver inautêntico.

No existir autêntico o ser tem consciência da questão ontológica, no existir inautêntico não. Em consequência, o existir inautêntico é caracterizado por um equívoco: o de pensar que Ser e existência são coincidentes. Existir autenticamente é saber disso. Existir inautenticamente é ignorá-lo, é procurar um paliativo para a dor da existência, é imergir no anonimato do "se" - o vive-se, come-se, gosta-se no lugar de vivo, como, gosto - ou seja, é destacar o aspecto impessoal do Dasein.

Porém, resta perceber - voltemos a esse ponto, que é fundamental - que não é por ser inautêntico que o ser ek-siste menos ou que ele não ek-siste. O processo da ek-sistência ocorre independentemente dela ser autêntica ou inautêntica. Tal como dizíamos acima, é preciso superar a tendência metafísica de compreender-se inautêntico, ou o fechamento do ser, como algo necessariamente negativo e o autêntico, ou a abertura do ser, como algo necessariamente positivo.

Percebida ontologicamente, sem que lhe imputemos valores, a queda, ou o fechamento do ser em uma condição de inautenticidade é, também, portanto, uma dimensão existencial do Dasein. É a situação e a condição da imersão do ser na vida quotidiana. E, cabe aqui, uma observação: como o Dasein já está jogado no 
mundo, ou seja, já tem na sua quotidianidade a sua condição existencial fundamental, o ideal não é perceber a queda como uma "queda" no sentido que a palavra evoca, na maioria das línguas, enquanto "caída" ou "tombamento", mas sim como uma despossessão. A queda é o que se produz no interior do Dasein. Não é exatamente o ser que cai no mundo, pois o Dasein já estava no mundo, à medida em que é um ente mundano, mas o ser que se percebe sem ser e que, simplesmente, submerge nesse conforto da impessoalidade.

A queda, portanto, se dá em relação a si e ao mundo. Os sintomas do falatório são os mesmos dessa queda. E, em consequência, podemos dizer que a Comunicação, análoga ao falatório, conforma uma experiência de queda, do Ser, na inautenticidade. A Comunicação é uma experiência que se torna possível no falatório: "O falar, quando é falado, é a Comunicação. A tendência ontológica da Comunicação é fazer os que escutam participarem do ser que é aberto, que é referido, por meio do falar que fala, do falar que está falando" (HEIDEGGER, 1976, p.223).

Esse "falar, quando falado" é o falatório. É o falar presente no mundo da vida. Em sendo falatório, a Comunicação, necessariamente, não partilha uma relação primária do ser com o ente sobre o qual está falando. Ela se atém, necessariamente, àquilo que está sendo dito:

A comunicação não partilha a relação primária do ser com o ente sobre o qual ele está falando, o ser-com-outros se envolve em um falar-como- outros e em uma preocupação com aquilo que está sendo falado. Nessa situação, tudo o que importa é aquilo que está sendo falado. O que se diz, o dito e a dicção, se empenham, nessa situação, como os garantidores da autenticidade e da adequação (da objetividade) do falar e da compreensão (HEIDEGGER, 1976, p. 223-224).

No falatório, portanto, a garantia da autenticidade, da adequação e da objetividade daquilo que é dito, não dependem daquilo que seria autêntico, adequado ou objetivo em relação ao ser do ente referido, mas, exclusivamente, do dizer, do dizendo, do dito, da dicção. Segundo Heidegger, o falar do falatório perdeu - ou 
jamais encontrou - sua referência original com o ente sobre o qual está falando:

E como o falar perdeu, ou jamais encontrou, sua referência original com o ente sobre o qual está falando, ele não se comunica possuindo uma referência ou uma apropriação originária desse ente, contentando-se em repetir e em passar adiante a fala. O falatório, dessa maneira, se estende a círculos mais largos, e assim se reveste de um caráter autoritário. A coisa é assim porque assim se a diz, assim ela é dita (HEIDEGGER, 1976, p.224).

E isso tem, por consequência, a sujeição, do mundo quotidiano, a esferas de autoridade que, sem sentido e sem origem compreensível, se afirmam como sendo toda a realidade: "Die Sache ist so, weil mane es sagt", a coisa é assim porque assim é dita.

Compreender a Comunicação sem as amarras metafísicas que são de seu uso habital - e que fundam sua epistemologia, como conhecimento reflexivo - resulta em perceber a Comunicação, portanto, não enquanto eficiência e eficácia de uma interação, de um discurso, de um dito, dizendo ou dicção, mas sim, exclusivamente, como um não-dizer; como a interação, direta ou mediada, e, em mediada, até mesmo mediatizada, de indivíduos, na comutação do banal e na construção coletiva da superficialidade e do não-dizer.

\section{Referências}

BLATTNER, William. Heidegger's being and time. Londres: Continuum, 2006, $195 \mathrm{p}$.

BOUTOT, Alain. Heidegger. Paris: PUF, 1989. 126 p.

CAVAlCANTE, Márcia de Sá. Notas explicativas. In: HEIDEGGER, Martin. Ser e tempo, 4. ed. Petrópolis: Vozes, 1993. p. 309-325.

GELVEN, Michael. A commentary on Heidegger's being and time. DeKalb (Illinois): Northern Illinois University Press, 1989. 230 p.

GUEST, Gérard. Être et Temps dans l'orbe de la 'Kehre'. In: CABESTAN, Philippe et DASTUR, Françoise (dirs.). Lectures d'Être et temps de Martin Heidegger. Quatre-vingts ans après. Argenteuil: Le Cercle Herméneutique, 2008. p. 49-72. 
GREISH, Jean. Ontologie et temporalité. Esquisse d'une interprétation intégrale de Sein und Zeit. Paris: Presses Universitaires de Frances, 1994. $522 \mathrm{p}$.

GUIGNON, Charles B. Heidegger's 'authenticity' revisited. In: DREYFUS, Hubert; WRATHALL, Mark, Heidegger reexamined. Nova York, Routledge, v. 1. p. 191-210, 2002.

HAAR, Michel. La pensée et le moir chez Heidegger. Les dons et les épreuves de l'être. Revue de métaphysique et de morale, n.4, p. 456-483, 1975.

. L'enigme de la quotidienneté. In COMETI, jean-Pierre; JANICAUD, Dominique (dirs.) "Être et Temps" de Martin Heidegger. Questions de méthode et voies de recherche. Marseille: Sud, 1989. p. 213-225.

HAUGELAND, John. Heidegger on being a person. In: DREYFUS, Hubert; WRATHALL, Mark (Eds.). Heidegger reexamined. Nova York, Routledge, v. 1 , p. $73-84,2002$.

HEIDEGGER, Martin. Being and time, trad. para o inglês de John Macquarrie e Edward Robinson. Londres: SCM Press, 1962.

. Sein und Zeit. Gesamtausgabe. [1927]. v II. Frankfurt: Vittorio Klostermann, 1976.

Être et temps, trad. para o francês de Emmanuel Martineau.

Paris: Authentica, 1985.

$\overline{\text { Gallimard, }} 1986$.

Etre et temps. Trad. para o francês de François Vezin. Paris:

Ser e Temp. 2 vols, 4. ed. trad. para o português de Márcia de Sá Cavalcante. Petrópolis: Vozes, 1993.

. Being and time. Trad. para o inglês de Joan Stambaugh. Albany: State University of New York Press, 1996.

Ser y tiempo. 2. ed.. Trad. para o espanhol de Jorge Eduardo Rivera. Madrid: Editorial Trotta, 2009.

MAGNUS, Bernd. Heidegger's metahistory of philosophy revisited. In: DREYFUS, Hubert; WRATHALL, Mark (eds.). Heidegger reexamined, vol. 2. Nova York: Routledge, 2002. p. 139-160.

PASQUA,Hervé. Introduction à la lecture de Être et temps de Martin Heidegger. Lausanne: L'Age d'Homme, 1993. 
RIVIALE, Philippe. Heidegger, l'être en son impropriété. Paris: L'Harmattan, 2010. 292 p.

\section{Fábio Fonseca de Castro}

Doutor em sociologia pela Université de Paris V (Sorbonne Descartes). Mestre em Antropologia pela Université de Paris III (Sorbonne-Nouvelle). Mestre em Comunicação pela Universidade de Brasília. Pós-doutorando pela Université de Montréal. Foi Secretário de Estado de Comunicação no Governo do Pará. É autor dos ensaios A Cidade Sebastiana. Era da borracha, memória e melancolia numa capital da periferia da modernidade (Labor, 2010), Entre o Mito e a Fronteira. Estudo sobre a figuração da Amazônia na produção artística de Belém (Labor, 2011) e Comunicação, Poder e Democracia (Labor, 2012). Atua na investigação das relações entre cultura e Comunicação na experiência social de populações amazônicas, com ênfase nos processos sociais intersubjetivos e com apoio das sociologias fenomenológicas e hermenêuticas e da ethnometodologia.

Recebido: 13.08.2013

Aceito: 15.11.2013 